\title{
Universal Science-Part IV
}

\author{
S. D. S. Deshapriya
}

\begin{abstract}
:
This paper is an outcome of a trial carried out to find a common methodology to address the different subjects together using circular thinking pattern which borrowed from Buddhism rather than addressing them separately. In addition to this, Buddhism which comprises of the perfect structure (body), immense innovative power and the broader ways of knowledge gaining are also utilized here to combine various subjects together.
\end{abstract}

Universal Science(US) reveals that, all are at a transitional stage hence it has been the reason for every thing in the universe to have mutually opposite duel characters, representing the (concept of) unique origin (Sataramahabuta) in one hand. Strength of US had been shown earlier, by addressing the universal secrets such as the revolving of planets, gravitational forces, occurance of common patterns in different things, such as rain, food circle etc. Further the new areas has also been introduced, such as the influence to the subjects by the common patterns at a higher level, need for exploring the whole area than one at a time, forming new theories using Buddhist texts, such as the universal conservation, effect of way of loading on bearing capacity etc. Hence, it is an occation of showing a link in spiritual \& material world in a different form.

Further the US which comprises of many talents \& techniques, emerges as the new life style to the modern world. Similarly, these techchniques are expressed here as, which can be practiced even by the most deprived sectors of the society, for their self determination irrespective of the political surround etc., while raising US, being the material version of Buddhism, as the new doctrine for the social liberation to the world in place of Marxism. It is also proposed to find the inherent path of US as the solution which could be found in 4 qdrnt plane for development \& to end the(nearly) by-polor political struggle in the country. Here in, it is further proposed through the US, for a change in the education pattern for the genious to come up easily. In addition to this,it reminds the need to be more selfless \& friendly to reach the climax in this (net) zero sum world for maximum gains through a spiritual approach. (Part I, II \&III were published in July2012, July2013\& January2014 journals respectively.)

\section{Forming theorems :}

US claims that the two opposites Theory as the first theorem of universe, and based on which all other, present scientific theories \& formulars areformed. It can be further clarified. As explained earlier, TO Theory is responsible for the repetitive pattern of the nature. Basically the equations \& the theorems are also the patterns (relationships) or the repetitions among different things (\& entities). Since scientific theorems \& equations are also there patitions, they are subjected to the TO theory \& based on it. Patterns play a vital role in developing US, hence giving ample benefites to the society. Hence In this circumstances, the application of patterns in varity of fields are further discussed here.

Accordingly US identifies that common patterns such as common qualities, concepts etc., are crossing over the subjects. These common patterns will act as common theories among the different subjects \& will result to form a common theory level above the subject fields. This will be a new concept and new dimension to the present science. Accordingly, as an initiation to this field, some common theorems such as the theory of simple oscillation, equivalent area, zero sum etc. can be developed for many subjects. These theories \& formulars will act as the parent (pattern) formulars to the formulars \& theories of individual subjects. For a example, equivalent area theory says that, when one factor is changed in one axis, other mutual factor is also adjusted automatically to compensate it, in order to maintain the net equivalent out come of the previous state. According to the above theory, when the normal flow is blocked in a stream, velocity increases there, to cater the

Eng. S.D.S. Deshapriya, C.Eng. MIE (Sri Lanka) B.Sc. Eng (Moratuwa), presently working In the Road Development Authority. 
water smoothly, which is coming from the up-stream.

Secondly, in a situation of sales going down, due to keeping the high profit margin, fare vender earns the same profit at a less profit margin, since his sales are increased accordingly. Boils' law also can be derived, directly from this equ. Theory. (other two theores are explained later).

This shows that the normal theories in science are the respective subjects versions of the above parent theories \& the formulars. Hence this will be a great advantage as far as the development of new theories are concerned, which can be made use as a short cut to form a new theories in various subjects. In this context, Since the Buddhism is having the perfect structure (body) it is comprised of many common patterns \& methodologies. Hence Buddhism can be used extensively to form many theories \& the methodologies.

Accordingly, the new innovation methods \& the parent theories such as two opposites, new innovations, universal conservation, Quantum jump etc. can be derived (as the material version) through Buddhist texts \& the philosophy. In addition to the parent theories, normal subject theories also can be developed. Nandi visalajatakaya can be taken as an example. According to the above story, more load was carried by the cattle, when it was treated in soft \& fariendly manner. This common pattern could be developed as a new (subject) theory \& directly apply to improve the bearing capacity of soft soil \& marsh as an environmental friendly solution. According to the above theory, bearing capacity of a soft material can be increased if the load is applied on it very soft manner. It is emphasized here, the effect of way of loading, to the bearing capacity of soft structures. Advantage of this theory could be harnessed, if the embankment is constructed using light material on marsh such as synthetic fabric waste, used tyres etc. Since the soft embankment materials transfer the load to marsh in soft manner, bearing capacity of marsh is increased accordingly, resulting to less settlement. Apart from the reduction of settlement due to light embankment material itself, this theory emphasizes here the further reduction, due to the soft nature of loading aswell, resulting to increase in bearing capacity. However, this has already been proved at the other extreme, by exhibiting pre-mature failure underadverse loading. Accordingly in the light of the pre-mature material failure as observed, due to tough way of treating, by means of fatigue \& sudden impact loading, has been a proved fact already, for achieving the higher bearing capacity aswell by softway of treating of which could be realized as the inverse character of the same. Further the phenomenon of higher static friction over the dynamic friction also will account to the new theory since showing high resistance, until it is un-hert.

In general this further shows the possibility of forming new scientific theorems, methodologies etc. through the pattern method and avoiding the costly research, deep analysis etc. in individual subjects.

Further in researches, the initial assumptions \& conceptual solutions can be formed successfully for early positive results at once or by less number of trials through the pattern method \& hence minimizing errors.

\section{Enhancing subjects through US}

US is so versatile to expand the prevailing subjects including their dimensions, concepts \& knowledge level etc. As an example to the subjects enhancement through US, subject of law is taken up here.

Present law is generally based on binary logic. However, it has been observed that, there are some law provisions which can not be included in the above logical base. Accordingly, the range of punishments (provisions of law) which are ordered by the court, for the almost similar offence can be given as an example, for such exclusion. Delaying the punishment by means of the suspended imprisonment, forgiving for some offences, forgiving to some offenders, change in the severity of punishment, appointing one accuse as the witness of the complenent, etc. can be shown as the range, which is applied for almost the same offence, which is committed. However this (punishment) 
range is seemed to be very needful, as far as the broadness of the subject is concerned \& the same is needful, in order to matching with certain situations. How ever, with respect to the binary logical frame, law (both enactment \& enforcement) should be very certain, hence above varing (nature) range is not acceptable. Due to the above fact, provisions of laws in general, are now left unsupported \& without a strong logical base. In this context, it is proposed to contain law, in the four quadrent logical frame, in order to cover all law provisions. Since the Buddhism is based on the four quadrent logical frame, it is the easiest way to take from Buddhism and to introduce this logical frame to the field of law.

This logical frame can be explained through an example, which will (almost) cover it resonabally. Any duel (two) combination may have four situations, which can be symbolized by $(+-),(-+),(+$ $+)$, \& (- -). In the normal binary base, both opposite \& both negative situations are not considered. But as far as the range of law provisions (as stated above) are concerned, both negative \& both positive situations are also needed, in order to include above provisions comfortabally with in the logical base. By widening the logical base upto the four quodrent frame, will facilitate further, to smoothen the application of law. Hence this action will further improve the versatility and the well functioning of law, covering all conflict situations \& all requirements.

In addition to this, efficiency \& the strength of trial proceedings could also be improved, by the Buddhist thinking pattern. In Buddhism, physical examples are very commonly \& amicabally being used to explain Damma (of which is nonphysical). Similarly, it is proposed to use physical examples in law field also, to strengthen the verdicts \& the trial proceedings. While proceding with the court cases, at present, it is normally referred to the verdicts, which were given in previous occations, for the verdict which has to be given for the case in hand. This practice is used at present, as a guide to consolidate further, the logical back ground \& to strengthen the arguments, in order to support \& justify the verdict, which has to be given. However, it is a situation of nourishing law further, with the help of law subject itself. In other wards, it is an enriching \& progressing of law by using internal tools \& sources of law. In the circumstances, Buddhism paves the path for improving law, with the support of other subject fields as well, as an external source. Hence, the examples are taken from other subject fields, to strengthen arguments \& to consolidate verdicts. According to the Buddhist thinking pattern, It has become possible, due to the common patterns, which are prevailing among different subjects. Hence it could be called as, the application of patterns in to law or entering law subject into the patterns era. Obviously, this will be an introduction of new dimention, concept to the field of law. This application will be very much appropriate \& decisive, for ending the most debatable \& sensitive issues, of having possessed very strong arguments, by the both (parties)sides, as well as in the situations of, no previous similar trials or verdicts are available for reference \& shortely, no resort can be found with in the law subject itself. Hence this pattern application will be very useful for the pioneering verdicts as well, where no previous verdicts are available for reference \& for making new laws to cover various situations.

This pattern application is elustrated here by an example, which could be used to strengthen the verdicts of human rights cases. Reference subject field, used from out side here, is the structural design, in civil engineering. In structural design, components, such as beams, collums etc. are designed first, followed by curtailing of rein-forcements at common areas, joints etc. This is a precautionary measure, taken in civil engineering, in order to prevent the total failure (collapse), due to the congession of bars at common joints etc which causing a barrier in load transferring. This can be applied as a common pattern, in order to differentiate (contrast) the stability of entirety vs the individual interest. Here in, the reinforcement bars, provided for the individual need (of beams etc.), are subjected to curtailing at common areas, for the safety \& security reasons (stability) of the building. Similarly, this common pattern shows that, the human rights provisions, which are imposed for the individual interest, could also be curtailed 
at the common social level, such as for the purpose of national security etc. In short even the human rights can be curtailed in a situation where the common social stability \& the national security is in danger (threathened) \& the national security prioritized over the human rights. Hence this will cut the chance of any individual, including terrorist to threathen the national security for his own interest or for any out siders intention.

Importance of pattern method is that, even in absence of such provision or prominancy in law, perhaps in the constitution, pattern method would provide (implied) back-up laws \& arguments independently \& automatically to redeem from any endangered situation. Further the applicability from different subjects to the field of law shows the versatility of law \& its' broadness to absorb any other (subject) matter into the law. In the other hand, the similarity (common pattern) used here, is a property or a natural behavior of a materials (concrete \& steel) which are subjected to an individual vs a common \& combined situation in order to give the verdict. Hence it is the nature as the maximum that the law or any other subject can be adhere to, for any severe issue, \& it is the (behavioural) nature (manner) of the nature which can be followed as the ultimate to find a nature friendly solution for human behaviors, issues also, as the last resort in order to ending all debatable \& contravercial issue. More than this, these patterns are the phenomenon of nature hence, none other than the laws of nature. Hence, incorporating the patterns into the law will cover the full spectrum \& scope of natural justice as well, as to its warded full meaning.

US as the material version, which empowered by Buddhism, urges to constitute law in the four quadrent logical frame as it's base (foundation) \& to incorporate other (subject) matters as well, by means of (common) patterns, in order to strengthen \& enhance the law subject (as an example to the subjects enhancement), of which guided by the Buddhist thinking pattern.

\section{Development:}

As far as the development is concerned, Patterns are important when arresting the complexity of the nature. It becomes more important, for arresting complex situations which aggravate together with the development. We all are proud of the prosperity, which achieved during the past. Thereafter we have experienced the un-development and poverty. According to the pattern thinking, the reason for this situation is the failure to continue practiing and updating the patterns (systems) un interrupted manner right through out up to the modern society. Systems and the development are in join hands together all the time. Without systems, no development \& easy comfortable living can be expected. Hence present undeveloped state of the country, demands for the systems as an urgent need, there by the development may notbe a miracleat all. Systems from top, will avoid the extra effort which required for attention, attending \& treating in individual basis. System will look after \& treat for all promptly. Lacking the systems (patterns) will reveal not the poverty but the poverty in thoughts.

More the systems more will be the development as well as easy \& the advancement of living. This can be realized when looking at the developed nations. No lesser country than Singapore provides enough evidence to support this fact.

Path for the development falls over the patterns (Systems). This reality, will insist us to identify Sri Lanka as a country which had been forcibly kept in poverty andundeveloped state even after being independent, until recently like a rubber ball pressed under water, in the light of having possessed a fertile soil \& a heap of natural resources all over the country, hence retaining all opportunities to come up at any little chance of exposure to the patterns through this pattern science (US). Systems will make the life easy and raise the country to the greater heights.

\section{Patterns in action:}

Coexistance of two opposites in nature is in many forms \& scattered every where 
covering both physical as well as non physical world. Effect of this coexistence is quite apperent in the physical world which exhibites as the repetition or the rotation. This repetitive behaviour is not limited to the physical world. In fact, it occurs as a result of the inter-action between mutually two two opposite qualities. When one tries to move, reaction of other is to move in the opposite direction, and resulting to rotate while being in the same location is a simple explanation to the above phenomenon of repetition in nature.

Similarly, the different forms of repetition can be observed in non physical world as well as among different subjects. In other words, even though the subjects are varied, common occurance \& common behavioural patterns are characterized among them. It is the repatition which occurs among various subject fields, even though they are different to each other in nature. Occurence of the difference in nature is not an arbiter \& indefinite because of the common patterns which are prevailing among different things. Hence the difference is also formed according to the patterns. Within limitations \& subject to the patterns, different things are formed.

Patterns will decide the manner \& the extent of the difference in nature. If the patterns are not in effect, extent of varityin nature could have been so extensive \& indefinite. Hence the occurrence of range of difference will be limited \& the patterns will decide the extent of variety. Even though the difference in nature is apparently spreaded in a wider range, it also had followed patterns while forming.

Because of the prevailing patterns as mentioned above, nothing could be formed newly. Even though so many new things are coming to the world with new technological advancement, they all are the different forms of the prevailing common patterns or the different form of the previous state. This has been explained earlier under the conservation property. As far asthe Sri Lanka is concerned, it may be a very encouraging situation for new innovationsdue to the fact that, by bringing all new innovations to the arms length. Due to the unknowing about the common patterns, have led the world to treat them as new things and new innovations.

According to the pattern thinking, different subjects are not the absolute differences, but just the different forms (shapes) only. In other wards various subjects are the different shapes (simulations) of common patterns or the effects of a cause(s)/or common patterns. Since Buddhism is the accomplished doctrine; it comprises of all common patterns which will form different subjects as respective subject version and the different subjects can be read through Buddhism by its' own language. That's why it was stated at the very beginning that, every thing can be contained into Buddhism.

This shows that the US is broad enough to take all new innovations \& all different subjects together through pattern thinking, with out treating them separately. In, other wards whole nature is apprehended by US which empowered by Buddhism.

\section{Life style \& the society :}

In the light of the path to attainnibbana, another track also can be developed parallelly as the material version of Damma of which will raise the man kind to the Modern Chac. Regime. This has been explained earlier. Reaching to the above climax is a gradual process and any individual from any level can enter into this track and gain maximum benefits. At the entry to the track, circular thinking will make the person more versatile to acquire a range of many talents, Just as the different form of life (\& not as separate talents). Hence he will be able to align \& adjust (tune up) his mind \& the body to the requirement as he wish for possessing more than a single talent. Accordingly he will acquire many talents over the others. As a result many individuals will come up from average, withseries of special talents \& techniques. This is the maximum personal development \& the building up of personality which can be acquired by a person. Apart from applying these at personal level, individual subject enhancement is also possible through the US. When US is applied as a common methodology, any present subject field 
will get brightened. Hence not to mention again the advancement that will be achieved by applying US in the field of education, individual profession etc. Hence any professional will be able to enhance his skills through the US.

Further in general, any individual or a group, specially the youth \& the younger generation can start practicing the techniques in this parallel track as a new life style of the century to reach the climax. Accordingly, US introduces the new life style to the present society in this modern world. (Further explaining of Improving the standard of life \& maximizing, using Buddhist techniques etc. will be given later.)

Thinking also will become easy \& powerful by understanding the pattern behavior of the nature \& training the mind accordingly. Then It can go very far than taking separately as in abstract thinking. Hence the different subjects which are far a part can be connected through pattern thinking. By realising the repatitive nature of things, pattern thinking will ease many subjects, increase capacity \& the understanding power. Hence unsolved problems \& unfound solutions in present science etc. will be found in US through patterns \& by considering all subjects together merely as the different versions rather than separate subjects as mentioned above. In this regard, being the cause \& effect theory itself, Buddhism may act as the parent subject to form various subject versions.

Even the capacity of managing the various subject fields can be improved by considering all are only as subject versions such as Engineering, Medecine etc. Due to the above fact, transferring the management from one subject to another may be quite easy as a common methodology irrespective of the subject field. In addition to this, as far as any persons duty is concerned, basically it is almost a repetitive nature in daily basis with a limited variety. Hence the work can be organized systematically. Further the training also can be arranged as more effective by concentrating to the frequently repeted duties \& the mistakes while at work. With regard to the innovations, new things are formed through common patterns according to the Chacreyachintana. As a result of repatitions (patterns) among different subjects, new innovations are emerged. All these potential powers will be accumulated to improve this parallel track which can be practiced as the new life style in the modern world.

Above parallel track which comprise of speedy techniques, can also be applied to up lift the mostly neglected \& deprived sectors of the society. These are so versatile that, Irrespective of the political or other outside environment, new life style comprise of these techniques could be practiced, even as a self determination of any secter of the society, declairing so by them-selves. In this context US itself will become the new theory of social liberation which emerges volunteraly without dividing the people nationally, teretorially or into any other divisions.

With regard to the innovations, one more method can be introduced which excels its power to enhance the social upliftment \& the liberation further.

After subjecting to extreme sufferance, hadled Patacharato attain Nibbana by changing her mind. In the other hand, Unless that physical and mental extremes, she would never be able to attain Nibbana. Physically also, new products are invented under extreme conditions such as extreme heat, pressure etc. Extreme conditions or peaks are a must to transform that to a new product and the intermediate conditions are not sufficient therein. Hence it is a another method of inventing new products to the world by subjecting to a extreme conditions (or peaks). Due to the above fact some experiments are done at the space because of some extreme conditions are not possible to achieve on earth. Further considering the formation of earth also, as a result of extreme heat and pressure which make it, to suitable for a new civilization on it, the strength of this method could be realized. Even the example of mammoty production is concerned, steel is subjected to a high impact blow at the extreme heat to form it correct quality \& shape.

This innovative method can extensively be used for social liberation as well. In this method, that the extreme conditions which were being subjected, byPatachara had led her to attend Nibbana. Generalizing the 
above situation, a common pattern could be developed as the (movement of) "simple pendulum theory" which says that "more the difficulty faced, higher will be the gain achieving". This innovative thinking could be applied to upgrade the poor \& deprived sectors of the society. Most advantage of this method is the, ability to apply their present deprived status itself as a previledge \& an advantage they have got, over the others, to climb more heights. Hence this theory will further enhance the above parallel track for social liberation of the poors \& under-priviledged sectors.

Accordingly the US as the ultimate science of the world, which comprises of immence innovative power \& featuring social liberation \& self determination to the deprived sectors will lead the whole world to the climax at them oder mchacrawarthi regime. Hence undoubtly the US as the material version of Buddhism will replace Marxism \& emerge as the new doctrine \& the practical path for social liberation to the modern world as forseen its replacement by a more superior phylosophy oneday, by the great phylosoper Karl Marx. Further US itself would bea tribute to his power of future vision.

\section{Problems Solving:}

With regard to the present social matters, US identifies that the drunkenness, addicting, suiciding etc., as a result of lack of personality. Hence the present practice of addressing each separately is not recommended by US as a successful method and the same has been identified as the main reason for the long dragging of these problems in the society with a increasing trendanually. Hence US questions the methods adopted to solve them by those who are involved at present. Hence US advise the main cause of lack of personality as the key problem to be address at the preventive stage as well as at this curative stage, collectively, through a multidisciplinary approach by all in order to end these social menace, rather than addressing separately.

However during past, Our ancestors were able to achieve a developed \& prosperous society through new innovative Buddhist thinking pattern by defeating such problems. Hence it is the ever only tested
\& proved methodology in the world for prosperity, due to all other development models have shown failures \& are giving troubles due to their imbalance nature. Being in line with our fore-fathers, US is introduced to the world again, as the most assured path for a balance development \& the prosperity.

As far as the social problems are concerned US would be able to address any present day problem, even though it hails from our ancestors time. For a example, Some debatable matters remained unsolved for long, since both sides are having strong points. Hence it's repercussion may be harmful to the society. Matters are become debatable, as far as we consider them in the binary logical frame. This is nearly a both positive case in the frame of four quadrantlogic. Hence summation can not be reached in the binary logic level just by agreeing to one side \& denying the other. In such a situation, US will address such issues successfully \& accordingly the summation has to be arrived only in the four quadrant space either by denying both \& finding a new solution at a common higher level or by compromising both side to a middle solution. This is the type of common pattern solution to these type of problems, when both sides are equally strong. As an example that, basically the Sri lankan society has been divided basically into two parties. It is not a healthy situation as far as the development is concerned. Hence in a four quadrant plane, ultimate solution can be foundby adhering to the authentic path of US which followed by our ancestors, in the light of being itself the future science valid for the whole world. Further at this moment US reminds the results, which gained so far within the binary frame as only the poverty \& the under-development since independence.

US further understand that, searching for a solution within the binary frame has ended up so far, with gaining only, a repetitive circle (Tattumaruwa) as the ultimate result instead of the development, since it is the repetiton which activates instantly, in a by-polar two opposites situation, through binary approach, while obeying to the TO theory. It is the binary plane itself, in which we are entrapped, as the reason behind for failing to understand so far, both repetitive "Tattumaruwa" \& 
earth rotation. As far as we are in this plane, we will never get answers to both the cases. On the other hand, in short, it is the binary approach again, which is responsible for the under-development \& poverty so far \& for dragging for so long this political debate un-solved. Hence it is only the out of frame $4 \mathrm{Q}^{\mathrm{DNT}}$ approach, which will qualify to stop this ever repetitive nature of country politics. Accordingly US insists that this as the high time for all to agree unanimously to apply US \& come back to our inherent path, of which followed by our fore-fathers to end this long dragging political issue. In the light of US being the future modern science, it is the wise decision which has to be taken by allpatriotics at this moment. Similarly any sensitive or critical problem for which the solution can not be sought in binary frame can be found the solution in $4 Q^{D N T}$ frame. Somebody will insist the need of two sided politics for a country as far as the democracy is concerned. It is true for a country, until its authentic path is not found. Hence Sri Lanka is in a well ahead stage compare to other countries, due to the fact that of possessing US as a future science of which had itself been able to identified as the unique authentic path for the country from our ancestors time \& implemented through Mahasammataya which agreed by all unanimously than the majority decision of Jana sammatawadaya (democracy).

\section{Science \& the Education :}

So far the development of science has been occurred while breaking the previously accepted assumptions, theories etc \& widening it"s base gradually. As far as the totality is concerned it is a backward march towards an unknown destination due to the risk of breaking the present theories also one day of which are accepted now. US reveals that, this backward march or the blind walk of present science can be ended, only by starting from the fundamental theory of coexisting of two opposites together \& based on it. Then the present science may start its forward march of detailing upto a known destination. At least this theory has to be taken as a initial hypothesis by the present science until it is disproved. Then it will be a very progressive approach as far as the future of the science is concerned. For this purpose, the present science has to be expanded upto four quadrant logal frame as the only way to accormodate two opposites theory which itself being a paradox.

Downward detailing from the totality is close to the nature ( $\&$ the evolution) \& It will reduce many separate studies which are tired some. Hence this forward march will have a direct effect to the present education system as far as the easy grasping of present knowledge by the children \& new discoveries are concerned. It will pave the path for more genious to comeup. As a example, the universal forces could have been found before the gravitational forces through this approach. In the other hand, US identifies that the education pattern prepared according to the above backward march, as one of the main reason for most of the children to be weak in science education in general \& only solution would be the science education giving close to the nature in forward direction with initial assumptions etc. Grasping knowledge would be quite easy in this method since more concern is given always to the total picture at the beginning \& followed by detailing. This will be realized when studying the childhood stories of Ienstine, whom had been called as an idiotonce. Being the forward march not yet a reality, it is the responsibility of the teachers \& the authorities concerned to identify the genious now from the weak list in the class room. Since this forward march will give the whole picture, while uncovering the universal secrets including the inherent limitations impose by the two opposites theory, will direct to end the progress at a certain level \& accordingly those genious will exceed Ienstine undoubtly in one day.

\section{Way to Extra gains :}

According to the US, co-existence of two opposites which is responsible for the whole dynamic nature of the universe ultimately gives netalgebric sum of zero value in every aspect. This means that, the whole universe is just at a rotation without any progressive move. Apart from this, nature is defective compared to the unique $\&$ perfect properties of satarabhuta. 
Due to the defective feature, one thing has to be sacrified to gain another of which will end up with net zero gain ultimately. This zero sum game appears in many forms in the present science also. According to Newton 'STheory, every action has a equal \& opposite reaction. Karl Marks said, every forwarding step of man kind would be a backward step as well.

According to the pattern thinking, Effect of Zero sum game will further be observed. At the personal level, all belongings \& every thing built upto date, will have to be left in presence of Sansara chakra \& will have to start from zero once again. Together with, Increasing the risk of loosing, gaining more \& more facilities is an other example. Growing danger equally, together with world development is an another aspect.

Effect of net zero sum as explained above is a universal phenomen on. Hidden static nature behind all planetary move vents including rotation, revolving etc. explicitesthis effect physically. Further in Universally it extends as the conservation in every aspect and no extra out come is possible. Combining with the mass and energy conservation theories, Two more new theories such as Theory of Uni conservation \& new innovations had been developed in part 3.

More than all these, it derives that, individually no rescue can be expected inthis zero sum \& ever static world. Only way to get a net extra gain would be trough a selfless \& collective efforts. This has to be realized as the additional (composite) strength gained by twisting a rope thanits individual fibers. Collective approach will be the only possible way to gain physical maximum before spiritual gainsin this material world.

Hence to be collective, they themselves have to give away selfishness. More being friendly, leaving selfishness, more will be the gains. Accordingly the friendly attitude, developed so far by pattern thinking will be further strength ened, due to being the only escape, as reveal through the US by the zero sum scenario. In the other hand, the friendliness which demands from man kind, until get away the present problems at globle level, will further be required \& become mandetoty in order to acquire extra gains in this zero sum world. Beyond this only remaining, will be the ever highest perfect immaterial gains at the spiritual world while beingfully selfless. Further the US understands that all these problems \& struggles in the world are due to the intermittent level where the man kind is performing now. Hence US is there to redeem the people \& to accompany them to the climax without leaving them anymore in this intermittent substanded level, which resulted due to the present science. It is the maximum possible level that the man can achieve in this material world, prior to the spiritual gains. Hence switching on to US has become compulsory from this science, since this is the form \& state of world with all these sufferences, poverty, tererism etc. as experienced now, that the present science can built \& hand over to the man -kind.

Due to the fact that we all are trapped in a zero sum cage and only way to a extra gain would be through collective effort, will urge the world to be more collective \& friendly as revealed by US.

This understanding one day will direct world to be selfless \& to end the undue competition in the light of all the countries are engaged in accumulating wealth now to face any attack or threat coming from another country. Growing friendly environment will diminish such need and the undue competition as well. In the other hand Collective minds will curtail the need for collecting wealth competitively. All effort could be focused towards the benefit of man kind rather than competing. Hence the climax will reach as a result of collecting all these energy.

\section{Conclusion:}

It has been shown here that all present scientific theories \& formulars are governed by the TO theory \& a common (pattern) theorem level has been formed based on the prevailing common patterns among the subjects. Accordingly as a example, a new theorem was formed by Buddhism as a new concept \& the advantage of this method is the ability to avoid cost involved for researching.

It has been further shown here the significance of patterns (systems) for development of a country. Techniques derived from Buddhism are so strong that those can be practiced as the life style to the modern society while being applicable 
to up lift the poor \& the deprived sectors of the society. Further, US has been identified here as the new doctrine for social liberation as well. Obtaining solutions at 4 qdrnt plane \& ending long dragging political problems were also discussed. Through a hypothetical approach, some suggessions were made to facilitate the genious to come up in their studies. Gaining more through being more selfless, was also shown here.

\section{References}

1. News Paper articles including "Mihindu Himiyange Amba Prashnaya" of Professor Nalinda Silva

2. News Paper articles of Buddhist Scholar, Professor Hettiarachchi etc. 